\title{
Experiences to Voluntarily Adopt Malaysian Business Reporting System MBRS: A Case Study of SMPs
}

\author{
Azleen Ilias ${ }^{1}$, Erlane K Ghani ${ }^{2}$, Nasrudin Baidi ${ }^{1} \&$ Zubir Azhar ${ }^{3}$ \\ ${ }^{1}$ College of Business and Accounting, Universiti Tenaga Nasional Malaysia, Malaysia \\ ${ }^{2}$ Faculty of Accountancy, Universiti Teknologi MARA Malaysia, Malaysia \\ ${ }^{3}$ School of Management, Universiti Sains Malaysia, Malaysia \\ Correspondence: Azleen Ilias, College of Business and Accounting, Universiti Tenaga Nasional Malaysia, Malaysia. \\ E-mail: azleens@uniten.edu.my
}

Received: March 16, 2020

Accepted: April 30, 2020

Online Published: June 29, 2020

doi:10.5430/ijfr.v11n3p1

URL: https://doi.org/10.5430/ijfr.v11n3p1

\begin{abstract}
The Companies Commission of Malaysia (SSM) has established the eXensible Business Reporting Language (XBRL) which is the Malaysian Business Reporting System (MBRS). This study examines the technological, organisational and environmental factors influencing the usage of MBRS among the practitioners. Using interview as the data collection among 12 respondents which are practitioners from selected Corporate Secretaries fom small medium practices (SMPs). Data from interview has analysed based on descriptive coding and pattern coding that developed by Technological, Organisational and Environmental (TOE) theory using the Atlas.ti. The findings of this study indicates seven (7) technological factors which are assurance for data quality, relative advantage and the availability of regulator's platform and system, limited tools and software, compability of format, compatibility of content and how the mTool could provide ease of use to the corporate secretary. In related to organisational factors, There are seven (7) challenges that can be considered discovered from organisational which are challenge to face attitude of preparers, limited practitioners that have own sufficient skills and knowledge, limited capable resources and preparers to manage the MBRS. In addition, there are six (6) environmental factors which are the technical support from regulator, the provision of incentive that should be given to the practitioners or SMPs, the effective strategies for promotion and educate practitioners method of voluntary submission. However, the lack of readiness on the use MBRS among trading partners and other stakeholder involvement would also challenge the adoption of MBRS. Therefore, this TOE factors would be important to practitioners to be ready on the enforcement of MBRS.
\end{abstract}

Keywords: MBRS, TOE, Atlas.ti, XBRL, Malaysia

\section{Introduction}

Recently, SSM has developed a system that integrated the XBRL for the purpose of business reporting that known as Malaysian Business Reporting System (MBRS). The purpose to develop the MBRS is to have centralised submission platform for Annual Return (AR), Financial Statements and Report (FS) and the Exemption Applications (EA) related to the FS and AR. MBRS is covered both financial and non-financial data which related with the Companies Act 2016, Malaysian Private Entities Reporting Standards (MPERS) and Malaysian Financial Reporting Standards (MFRS). Together with the implementation of MBRS, there is a need to develop the XBRL taxonomy which known as SSM XBRL Taxonomy (SSMxT) which is act as dictitionary that include elements of FS, AR and EA that has been embedded in mTool. In preparing the document, SSM has developed ready template that based on Microsoft Excel which is as mTool. With this ready template, companies are able to prepare the document that known as XBRL format whether online and offline. After prepare the XBRL format, companies need to submit through submission platform which is MBRS portal. Based on XBRL concept that has been embedded in MBRS, one of the advantage is to reduce error in data that has been key in due to validation check on the data. Based on the implementation of MBRS, the main role that important is Company Secretary that will act as lodger to submit the XBRL document. In addition, the maker of document can be Company Secretary and Company Secretary Assistant and they are responsible to prepare and upload the XBRL document. In relation to the maker, external users that have the right as a maker role could be act as a maker that associate with the lodger. In related to MBRS, the practitioners such as accountants or auditors could also be part of MBRS implementation as maker, while Company Secretary as 
lodger.

From the implementation of MBRS, the concept of XBRL has shown in order to ensure the benefits will experience by the regulators and users of MBRS. The XBRL is "An open standard which supports information modelling and the expression of semantic meaning commonly required in business reporting. XBRL is XML-based. It uses the XML syntax and related XML technologies". (Hoffman, 2006, p.1). Bergeron (2003) defined XBRL is "an extension of Extensible Markup Language (XML), which is a language that has been extended to business reporting standards". In related to business reporting, Debreceny and Gray (2001) has defined eXtensible Markup Language (XML)-based Web-based business reporting environment which is an XML-based specification for efficient automated retrieval of financial information. XBRL has tremendously developed which are in the US, Australia and Netherlands, UK, Japan, Denmark, Europe, Russia, Belgium,France, German, India, China and Singapore (Ilias, Ghani \& Azhar, 2019). The development of XBRL has bring benefits which is related to produce continuous reporting (Weber, 2003), cost reduction (Liu, Luo, Sia, O'farrell \& Teo, 2014), greater accuracy and speed when collecting, storing, exchanging and analyzing this information (Piechocki \& Servais, 2010), reducing information asymmetry between market participants, reducing costs of equity, increasing market liquidity (Klimczak, 2019) and improves public companies' earnings release efficiency and mitigates earnings management (Hsieh, Wang \& Abdolmohammadi, 2019).

There is a need to implement XBRL in Malaysia due to the development of XBRL in lots of countries which has shown impact on various areas such as in quality of business reporting, continuous auditing or decision making. In the past, studies has done in various countries to investigate the factors that impact the adoption of XBRL as in UK (Mousa, 2016), New Zealand (David, 2016; Cordery, Fowler \& Mustafa, 2011), Australia (Troshani and Doolin, 2007) and USA (Henderson, Sheetz \& Trinkle, 2011) and Malaysia (Ilias, Ghani \& Azhar, 2019). Most of the studies concerned on the early stage of adoption as well as the adoption process which identified drivers and challenges of adoption utilise the Technological, Organisational and Environmental (TOE) based on DePietro, Wiarda and Fleischer (1990) and DOI theory (Rogers, 1983). In recent study done by Ilias, Ghani and Azhar, (2019), the focused on the adoption process for four regulators in Malaysia without concerned on the other stakeholders such as practitioners. There are four regulators in Malaysia that have developed the system that related to XBRL which is Bank Negara Malaysia (BNM), Securities Commision (SC), Lembaga Hasil Dalam Negeri (LHDN) and Suruhanjaya Syarikat Malaysia (SSM). However, this study focus only the system developed by SSM which is known as MBRS. This is because MBRS is the system that operated for submission business reporting for private and public entities that registered with SSM. In addition, the usage of MBRS is started with practitioners particularly by Corporate Secretaries. Thus, Corporate Secretaries fom small medium practices (SMPs) in Malaysia has been selected to share their experiences in the early stage of implementation. The study done in Australia (Troshani and Doolin, 2007), which applied convergent interview that have understand the scenario of the XBRL implementation with the TOE theory. Thus, this study will focus on Corporate Secretaries from SMPs by applied TOE theory. With the problem statement, the study is carried to examine the factors that influence the usage of MBRS among practitioners which particularly to examine the technological factors (RO1a), organisational factors (RO1b) and environmental factors (RO1c) that influence the usage of MBRS among practitioners. The next section, Section 2 presents the literature review. This is followed by Section 3 that provides the research methodology and then the findings and discussion in Section 4. The final section, Section 5 concludes this study.

\section{Literature Review}

\subsection{XBRL vs MBRS}

XBRL is one of the tool that improve the limitation of traditional business reporting via the used of internet. The limitation that has been raised by past studies such as Janvrin, Pinsker \& Mascha (2011) raised on the information in PDF is not indexed by search engines, while HTML as an information dissemination medium, cannot uniquely identify reporting data elements and effectively translate data. Due to the limitation, the existence of XBRL has improved the tradional reporting as mentioned To better exchange information, XBRL can facilitate the exchange of information over the internet (Lymer, Debreceny, Gray \& Rahman, 1999). Studies have shown that XBRL can be more useful for decision making compared to PDF or HTML (Ghani, Laswad and Tooley, 2009).

There are studies that related to study done with XBRL adoption with the business reporting which bring benefits such as improve the voluntary reporting (Efendi, Smith \& Wong, 2011), continuous auditing and assurance (Plumlee \& Plumlee, 2008; Alles \& Gray, 2012; Shan \& Troshani, 2014), reducing information asymmetry (Yoon, Zo \& Ciganek, 2011), ease earning management (Hsieh, Wang \& Abdolmohammadi, 2019), efficient forecasting (Liu, Wang \& Yao, 2014), timely disclosure (Zhou, 2019) and effective information supply chain (Liu et al., 2014). Due to 
the realisation of benefits, SSM has developed the MBRS that adopt the XBRL in the preparation of AR and FS. In Malaysia, there are few studies that discuss on the adoption of MBRS such as Ilias, Ghani and Azhar (2019), Wahab (2019) and Uyob, Bahador and Noh (2019). In related to MBRS, XBRL has been embedded with the system through the XBRL taxonomy which produce XBRL instance document. Stantial $(2007$, p. 2) recognised XBRL taxonomy as a barcode for financial statements. The taxonomies are based on accounting standards and regulatory reporting by national or even international standard setters as a key element of regulating national and global business activity (Troshani \& Lymer, 2011, June). With this XBRL taxonomies, there is validation process to ensure there is less of errors on the data (Plumlee \& Plumlee, 2008). While, XBRL instance document is the business reports that has formatted with XBRL tags (Troshani \& Lymer, 2011, June). Therefore, SSM has developed the MBRS that incorporated with XBRL taxonomies that has been embedded in mTool in order to produce XBRL instance document (Ilias, Ghani \& Azhar, 2019).

Prior to adoption of XBRL in various countries, there are studies that related with the awareness of XBRL. There has seen lack of awareness (Troshani \& Rao, 2007; Nel \& Steenkamp, 2008; Pinsker, 2003; Cox, 2006; CFA, 2016), intention (Henderson, Sheetz \& Trinkle, 2012) and understanding (Pinsker, 2003; Stantial, 2007; Weber, 2003; Dune, Helliar, Lymer \& Mousa, 2009; Venkatesh \& Armitage, 2012; Steenkamp \& Nel, 2012) on the implementation of XBRL. In Malaysia, there is also shown lack of awareness (Ilias, Razak \& Razak, 2015) with lack of adoption among companies (Ilias \& Ghani 2015). However, there is also perceived impact towards the adoption of XBRL (Ilias, Ghani \& Azhar, 2017) in Malaysia even though there is voluntary in the preparation of FS in XBRL format.

\subsection{Factors Towards the XBRL Adoption Based on Technological, Organisational and Environmental (TOE) Model}

The early study that investigate the factors to adopt the XBRL is done in Australia by Doolin and Troshani (2007) among institutional members of XBRL Australia and the local XBRL consortium. While, Cordery, Fowler and Mustafa (2011) has explored the factors that influence the non-adoption scenario of XBRL in NZ. Compare with the recent study in NZ done by David (2016) investigated the reasons of not adopting XBRL by business and professional organisations and the New Zealand government and the non-adoption implications for XBRL stakeholders. In study done in UK by Mousa (2010) had investigated an e-government adoption process of XBRL for two different regulators. Recently, the study done by Ilias, Ghani and Azhar (2019) has study the adoption process of XBRL among four regulators in financial environment in Malaysia. While, study done by Suriakumari (2018) has identified the internal and external factors that would drive the perceived timeline to adopt XBRL amongst Public Listed Companies (PLC) in Malaysia.

Based on various studies in related to XBRL, there are mixed of factors that discovered from different studies which applied the TOE framework (DePietro et al., 1990) from three contexts (technology, organisation and environment) from an organisation's perspective, which might influence technological adoption. Firsly, the common technological factors are relative advantage (Mousa, 2010; Cordery et al., 2011; David, 2016; Ilias et al., 2019) , compatibility (Cordery et al., 2011), complexity (Troshani and Doolin, 2005; Troshani \& Rao, 2007; Henderson et al., 2012; Ilias et al., 2019), trialability (Doolin \& Troshani, 2007; Cordery et al., 2011; David, 2016; Ilias et al., 2019), observability (Doolin \& Troshani, 2007; Ilias et al., 2019), stability (Mousa, 2010; David, 2016), cost of software (Dunne et al., 2013) and cost of XBRL solutions (Troshani \& Doolin, 2005), compatibility of XBRL taxonomy (Ilias et al., 2019), stability of XBRL taxonomy (Ilias et al., 2019), standardisation of XBRL taxonomy for internal and inter-organisational (Ilias et al., 2019), producing stable XBRL instance documents for intra and inter-organisational aspects (Ilias et al., 2019) and standardisation of XBRL submission (Ilias et al., 2019).

Secondly, the organisational factors are related to expertise, skills and knowledge (Mousa, 2010; Steenkamp \& Nel, 2012; Henderson et al., 2012; David 2016), management support (Felden, 2011; Cordery et al., 2011; Steenkamp \& Nel, 2012; David, 2016), organisational champion (Cordery et al., 2011; David, 2016), organisational resources (Troshani \& Rao, 2007; Mousa, 2010; Cordery et al., 2011), organisational readiness (Doolin \& Troshani, 2007) and change of program sponsor (David, 2016).

The thirdly, the environmental factors are consist of of regulatory measures (Cordery et al., 2011; Henderson et al., 2012; Steenkamp \& Nel, 2012), government support (Mousa, 2010; Cordery et al., 2011; Steenkamp \& Nel, 2012), trading partner (Henderson et al., 2012; Garner et al., 2013; David, 2016), normative pressure (Henderson et al., 2012), critical mass (Mousa, 2010; David, 2016), global pressure (Troshani \& Rao, 2007), availability of information (Doolin \& Troshani, 2007; Mousa, 2010), accessibility to external support (Mousa, 2010), local adoption strategy (Troshani \& Rao, 2007), success stories (Troshani \& Doolin, 2005; Troshani \& Rao, 2007; David, 2016), priorities of accounting standards (Troshani \& Doolin, 2005; Troshani \& Rao, 2007), security problem (David, 2016), 
knowledge gap (David, 2016), change of laws, rules and regulations (David, 2016), work culture (David, 2016), economic condition (Steenkamp \& Nel, 2012; David, 2016) and effective stakeholders' involvement (David, 2016).

By comparing with the current study, these factors are discovered from the early process to adopt XBRL among regulators, government agencies and potential decision makers. This current study has applied TOE theory to investigate the factors that existed through practitioners' experience at the early stage of voluntary adoption of XBRL via MBRS. This TOE is relevant to use for individual perspective because individual experience in usage of MBRS would also influence the decision to continuously adopt MBRS by SMPs in Malaysia. Supported by Bakajic (2015), both perspectives of the individual and organisation will need to emerge in order to examine the organisational adoption. This is because individuals are part of decision makers that played the role in the context of the firm that could influence future decisions. Furthermore, Wang, Wang and Yang (2010) has also provides a good starting point when analyzing and considering suitable factors for understanding the innovation-adoption decision. Most of studies for XBRL has applied TOE theory in order to understand the adoption of XBRL among organisation which discovered drivers and challenges such as Troshani and Rao (2007), Henderson, Sheetz and Trinkle (2012), Doolin and Troshani (2007), Troshani and Doolin (2005), Cordery, Fowler and Mustafa (2011), Mousa (2010), David (2016) and Ilias (2019). Therefore, practitioners such as corporate secretary or auditors from the SMPs are relevant as individual in MBRS adoption.

\section{Research Methodology}

\subsection{Respondents}

This study chose practitioners from selected SMPs to be the respondents in this study. This is because practitioners also play important role in the adoption of XBRL as they are also part of stakeholders (Troshani \& Rao, 2007; David, 2016). The selection of respondents was based on purposeful sampling due to involvement that have experience in using mTool to prepare AR and FS as well as submission through MBRS. There are 12 respondents has been selected which they play their role as maker and lodger of XBRL instance document through MBRS. All respondents has been known by AC1, AC2, AC3, AC4, C1, L1, N1, RJ1, RJ2, RJ3,RJ4 and G1.

\subsection{Data Collection}

This study relied on semi-structured and open ended interview was done done directly with 12 respondents from May 2019 until November 2019. This study employed face-to-face interviews, whereby data collection was done directly with the respondents from SMPs. To seek permission, official letter was sent to each respondent before the data collection, followed by a phone call to confirm on the volunteer to participate. The questions were prepared or adapted when necessary, and change with any doubt, which can adapt based on stakeholders' adoption on the use of mTool and MBRS.

\subsection{Data Analysis}

This study conducted data analysis as suggested by Miles et al. (2014), which consisted of both preparation and analysis of the data with the assistance of Atlas.ti as show in Diagram 1. The researcher read and understood each word and phrase in the transcription from the 12 respondents. The understanding and interpretation of researcher has developed based on descriptive coding as suggested by Miles, Huberman and Saldana (2014). Next, the second cycle coding is conducted by utilising pattern coding, which is to group the summaries into smaller number of themes. The pattern codes are explanatory or inferential codes that identify an emergent theme (Miles, Huberman and Saldana, 2014). Therefore, the second cycle coding is made based on the definition for pre-determined and undetermined factors. The factors for technological, organisational and environmental context has been determined based on the past studies. 


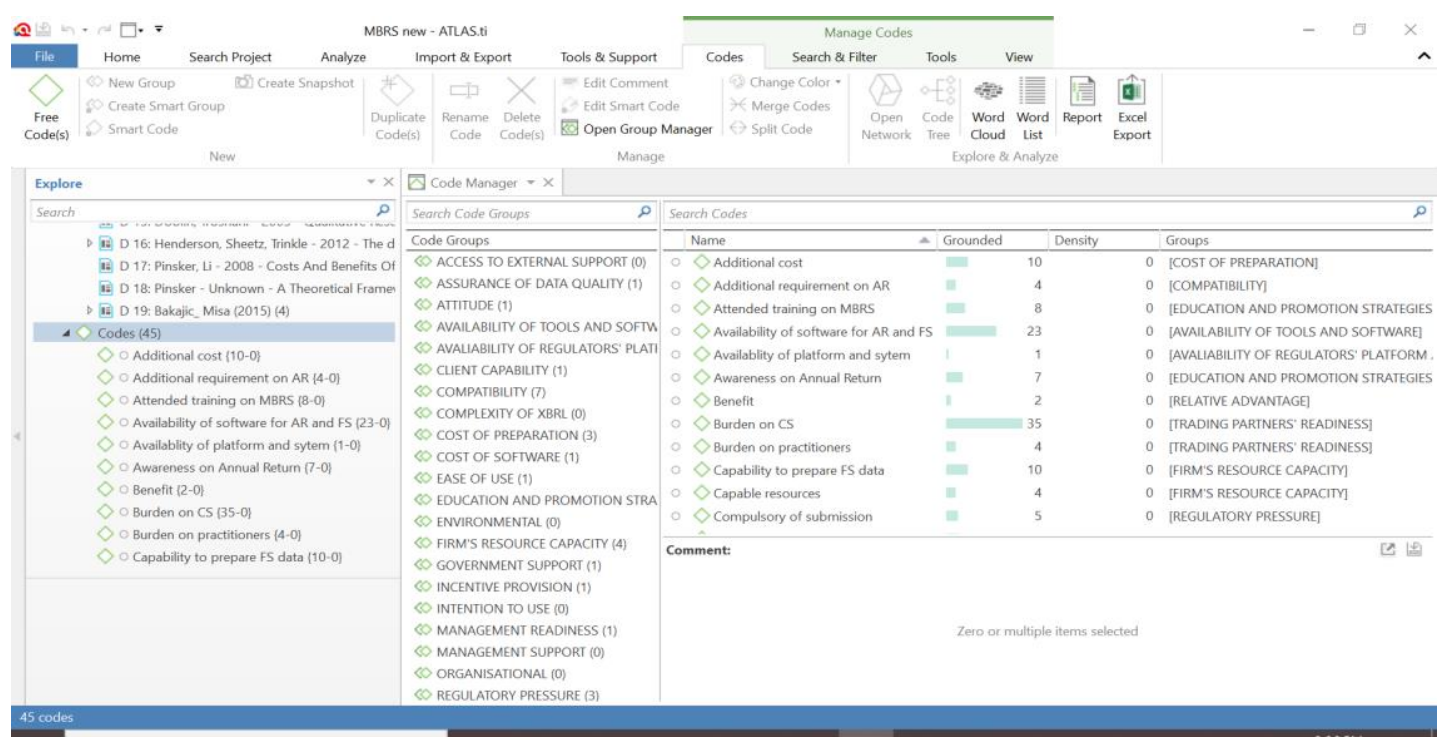

Diagram 1. Sample of process for Atlas.ti

4. Findings and Discussion

4.1 Technological Factors
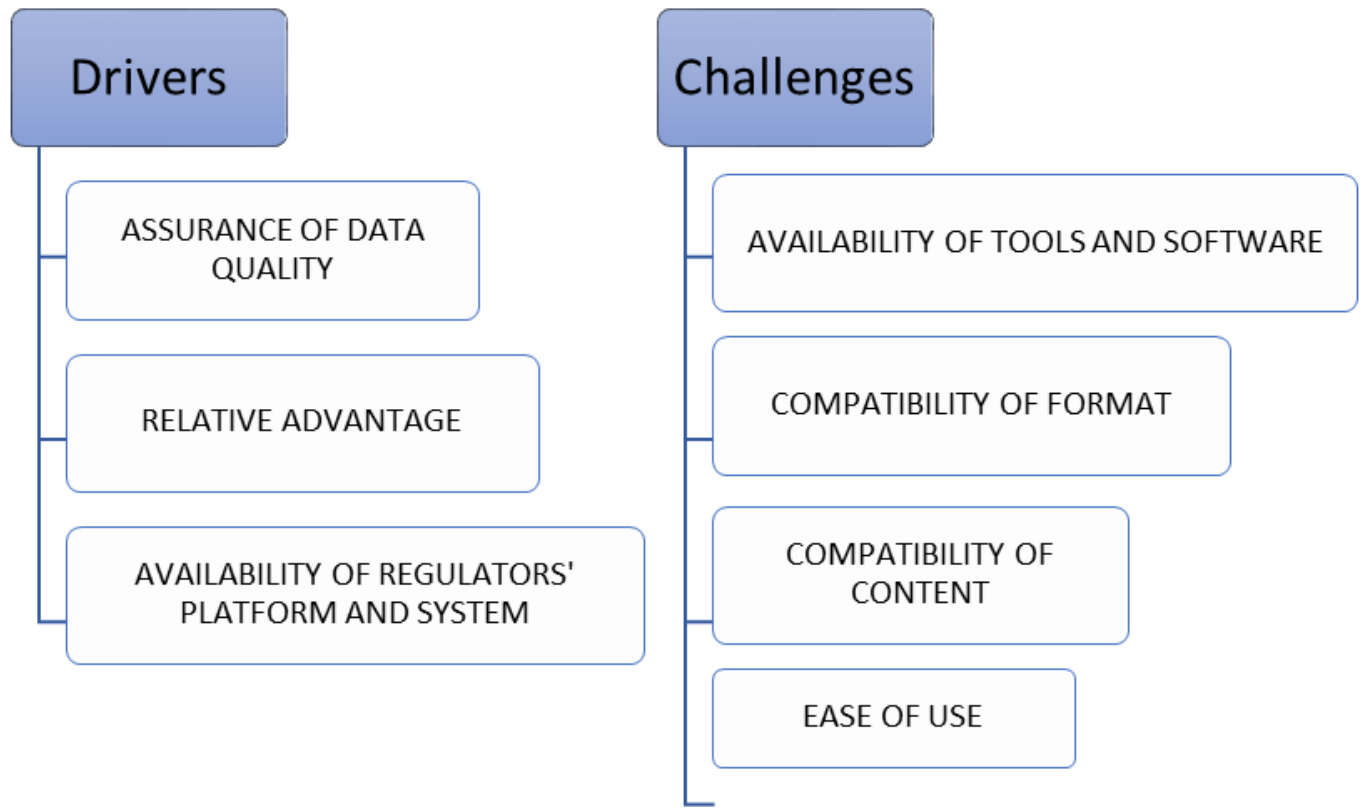

\section{Relative Advantage}

There is a need to be aware of the relative advantage of the implementation of MBRS. This could encourage the understanding of why MBRS has been implemented by SSM. This could encourage the practitioners to have the fastest process to deal with the regulator as mentioned by respondent $\mathrm{C} 1$, "we want online to be fast". Respondent RJ1 also mentioned on the advantage to implement MBRS, "If we do it manually, we cannot detect any errors or fraud. From my experience, there is one Singaporean director that uses I/C Singapore. But, MBRS reject its I/C immediately since it is Singapore. If the details are not completed, it will become error. We must ensure all the information if fully complete for it to be accepted. There will be query but I like it that it couldn't be submitted if it is not complete. So, we can actually know which part is wrong. We wouldn't know if we do it manually. When the 
system check the errors, which is more precise". Therefore, the relative advantage can be considered as driver to the adoption of MBRS seen MBRS able to provide advantage on the submission of AR and FS.

\section{Assurance of Data Quality}

In understanding the intention to adopt MBRS, practitioners are concern on how XBRL taxonomy that embedded in mTool could ensure the quality of data. This XBRL taxonomy could reduce the possibility of erroneous data that will be key in through mTool. This factor will ensure practitioners could benefit from the implementation of MBRS. As this could be seen from the respondent L1 that mentioned, "Before, if we submit over the counter the audited report, they will return if there are any miscalculations. Now, there will be no miscalculations because we generated the report using MBRS. There will be benefits which are we don't have to make things twice. If we miscalculated in the Auditor's Report, definitely you will know it because it is not balanced". This also has been concerned by respondents $\mathrm{AC} 1$ also mentioned on the error rectification, "Because for submission of the report, if there are any errors, SSM will not check it since they don't have any amendments or queries. It'll just go straight to the system. That is why we need to balance the items in the balance sheet. "This assurance data quality is produced through the validation process that embedded from XBRL taxonomy that could reduce the burden of practitioners in preparing the annual return and financial statement and reports. Therefore, assurance of data quality as driver to the adoption of MBRS which MBRS could deliver a high quality data.

\section{Availability of Tools and Software}

In addition to the drivers to adopt MBRS, challenge found by practitioners that could raise to the SSM to be more aware of the development of MBRS. Since the adoption of XBRL through MBRS is still new in Malaysia, there are limited tools and software that can be used by the regulator and practitioners. Thus, there is still uncertainty in the availability of tools and software among practitioners at the early stage of adoption of MBRS. In SMPs, there is corporate secretary software that is used and it is still uncertain how XBRL can be embedded to ensure the preparation of XBRL instance document. Respondent $\mathrm{C} 1$ has raised an issue related to the software, "Because we have system we use I think. S2000 if I'm not mistaken. A lot of company secretary is using that. It makes our work much more easier. Okay from S2000, can it be integrated with MBRS tools? I think we just waiting for the software. I think it is easier with that". Other than corporate secretary software, there is also audit software that could be possibly integrated with MBRS to produce XBRL instance document. Respondent $\mathrm{C} 1$ mentioned that "AXP is one of it. I think its CCH. I don't know it's ready, or workable. They show us that confirm is can. But in our practice, we need to fill up work. If anything go wrong, or any cut how to do and how to charge also". But, there is a need to ensure the cost from the tools and software, which respondents G1 has raised on "But then for the charge, you need to buy the software. Because this is to make sure that the audit programme is linked to the MBRS. So, you need to buy the features. Actually, Mr Wong got a vendor". Respondent RJ1 also agreed on the integration of MBRS with the software will need to incur a cost when they mentioned "that is why we need a software that can integrate all audit systems, to be integrated with MBRS. Like right now, if you want to generate the data from your system directly to mTools, it is quite expensive". Practitioners would also need this due to having the fastest process to produce XBRL instance document that agreed by RJ2 "there should be a system like that since everyone wants a quick process". Based on this finding, the limited of availability of tools and software will be challenge to practitioners due to lack of integration of software with the mTool prepared by regulator.

Availability of Regulator's Platform and System

Even though the limited availability of tools and software, SSM has prepared a platform and system that could help practitioners in starting to use MBRS. The MBRS has been developed together with the mTool that has a ready template. This could be driver to practitioners when the respondent L1 has emphasised on this matter, "It takes time to generate but one good thing is that when you prepare financial statement, using the tools, you don't need to online. Although the data is how bad the tool is, using MBRS doesn't require ID. If the client have the links, if the website is down or whatever, you cannot do it at all. For this tool, anytime is convenient to you, you can access it. It is downloaded". MBRS has been developed together with a ready template and offline system which could help and assist all practitioners to use in order to prepare and produce XBRL instance document. Therefore, this readiness of plartform and system by regulator could ease the preparation of XBRL instance document for AR and FS.

\section{Compatibility of Format}

In related to the ready template that uses from mTool, practitioners also concerned about the compatibility of format and content. The challenges among practitioners when they consistently raised on how the traditional reporting format will compatible with the format and content of mTool. The format should be consistent with the requirement of SSM that could easily use and understand by practitioners. Based on respondent AC1 which concerned on the format that the "format is not really eye-pleasing and supported by respondent $\mathrm{AC} 2$, "But, the way we see it, it looked like it is upside down, and quite messy". With this could be challenge to practitioners in order to smoothly 
adopt the MBRS.

\section{Compatibility of Content}

In related to the content, most practitioners has provided comments on the compatibility of content that fit the requirement in preparing AR and FS. The content for AR could be seen as compatible with traditional format and not as challenging when preparing FS. As mentioned by respondent AC1, "for annual return, there is no problem in generating it since the items are not complicated" and respondent L1 stated that "if we use it for annual return, there is not much problems. Because annual return comprises more secretarial part".

However, the content could be a challenge to practitioners in order to ensure they could use to prepare the XBRL instance document. The challenges happened due to difficulty to understand with the terms used in the ready template from mTool. The term issue has been raised by respondent N1, "for us who rarely look at FS might not fully understand it. When we want to key the FS into MBRS, we need to choose which one. The words or terms used might be confusing to some". Consistent with respondent AC1 when they agreed that "the terms are confusing especially when we wanted to key in the information". Besides of term that used, items that need to key in by practitioners also related to the content. The content in FS has shown so many items which could impact the confusing among practitioners. The respondent $\mathrm{AC} 1$ and $\mathrm{AC} 2$ had provided their experience when they stated that "but for financial statements, it is tough. There is more details in details. That is what we're stressing over". Due to many items, respondent RJ1 would agree if the items should only cover the main items of FS, "I think SSM should only require us to do key financial items (KFIs) first. Just enter the total first". Therefore, this factor could be challenge to practitioners as maker and lodger to the XBRL instance document for AR and FS.

\section{Ease of Use on mTool and MBRS}

With the compatibility of format and content, there is issue on how practitioners could experience of using the mTool and MBRS. Due to the experience to use, respondent G1 stated the complicated of mTool. They stated "I will ask for somebody else to do it. If those unaudited one is simpler, only then we can do it. For those audited ones, I don't think we are able to do it. Those are very complicated". With related to the choice to use, respondent L1 has told on the choice of use MBRS. They mentioned "I have to do it first before they do. I can do accounting analysis, I can do it. So, I got no choice, even with accounting basic, it is difficult". While a new system could also bring confusing and unconformable to future practitioners by stated: "MBRS might cause discomfort to some because it would probably drag the process". Furthermore, the format and content to be key in by practitioners would provide discomfort due to the tedious items and terms that used. Respondent AC2 mentioned on "some people who use the system may directly forward it to MBRS. But, for those who didn't, they need to key in one by one, which is quite tedious". It has been added by respondent AC4 which stated "because it is really tedious. For one item, there are many subitems". Therefore, practitioner has feel challenge to use the mTool and MBRS due to format and content.

\subsection{Organisational Factors}

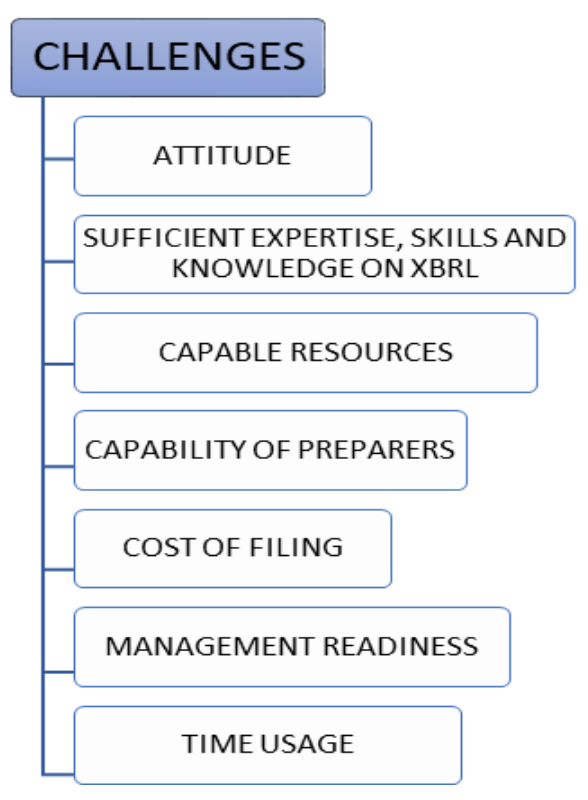




\section{Attitude of Preparers}

In ensure the intention to adopt MBRS among practitioners; factors influence the organisation, which is SMPs that responsible for preparation of AR and FS. Firstly, the attitude of practitioners on how they can fear with the new system that need to be followed. With the adoption MBRS, some practitioners would be afraid with any additional cost or penalties that will be given by regulator. The feeling of fear has actually impact the practitioners as suggested by respondent $\mathrm{AC} 2$ and $\mathrm{AC} 3$, because for submission of report, "if there is any errors, SSM will not check it since they don't have any amendments or queries. It'll just go straight to the system. That is why we need to balance the items in balance sheet. But If any error, we don't make amendment, we'll need to do ratification. For ratification, it will incur more cost. We need to re-do, make additional payment. That is why it is risky for us to truly make financial statements". Basically, practitioners could have a fear of making error in providing data in FS due to any additional payment. Thus, the implementation of MBRS could give fear to practitioners which may affect the intention to adopt. Respondent N1 has also emphasised "for MBRS, we didn't want to use it if possible. Lodgers have to use it, but for preparers or also known as makers, they need to be meticulous to avoid making too much mistakes. If there are mistakes, it is quite troublesome that we need to correct it. The compound liability is put on the shoulders of the makers. When the error always happen, later we might be bankrupt. So, who wants to be preparers? Many people didn't want to do it". Therefore, attitude among practitioners could be challenge to adoption of MBRS. This is due to attitude of change to a new system could challenge the readiness of MBRS among SMPs.

Sufficient Expertise, Skills and Knowledge on XBRL

This is the common issues that existed prior to the implementation of MBRS. Even though practitioners has not involved in developing the mTool and MBRS, practitioners has also concerned on their expertise, skills and knowledge in preparing the AR and FS using the ready template of mTool. From respondents perspective which mostly said about how corporate secretary as maker and lodger could not have enough knowledge and skills in preparing the submission for FS.

The challenges on preparing the document from mTool from AR is not challenge to corporate secretary. This is because the data that need to key in is not related to accounting concept. This could refer to respondent $\mathrm{C} 1$ : "Normally, the company secretary they do not have such knowledge in filling those information. There is a lot of information and details that need to be understand. Therefore, it is not easy". As also by respondent G1: "Company secretary, I do not have any other accounting background. I just learned a little bit last time, accounting paper". As corporate secretary, respondent L1: "For secretarial staff of mine, they do not have accounting background". Furthermore, in related to the format and content of FS, it will provide more confusion as they do not have any sufficient knowledge as respondent RJ3: "since I did not have much knowledge about annual report, it is quite confusing for me".

However, corporate secretary as the main role in preparing the document for MBRS has limited knowledge and skills which giving confusion to most of them. This is because most of data required are financial audited data that need peoples that expert in accounting. The respondent $\mathrm{C} 1$ has mentioned, "We need to wait for audit part. Because a lot of information will be done by outside source". Respondent G1 also support that the role of corporate secretary and auditor could be different in using the MBRS with limited knowledge in accounting. As stated by G1: "we didn't do the details but every day we need to flip through the accounts to do the submission. We need to ensure that the Director's report are signed, the date are okay, the balance sheet, the $P \& L$ and everything is in there. It looks familiar but somehow or rather if you believe you want to key in the details, you wouldn't know where to put them in. Because we are not auditors. Actually, we didn't turn up with the report by ourselves but we only look at it because we are the person that need to look at it". Thus prior to the adoption of MBRS, practitioners really need to equip with sufficient knowledge. This is because respondent $\mathrm{L} 1$ mentioned on "for FS, the very first difficulties that they encounter is that whether their staff are equipped with adequate knowledge about accounting. Mostly, the staff is not well-versed with accounting terms. Not even know how to read the Auditor's Report". With a limited understanding on the accounting term, this could bring wrongly key in data and items. Respondent AC1, AC2 and AC3 has mentioned the issue that related to: "It might be tough for those who did not have basic in Accounting. Even the terms is confusing.It is more difficult since we are not well-versed in accounting knowledge". This could be burden to non-accounting peoples which respondent $\mathrm{N} 1$ emphasised "Those with non-accounting background wouldn't see anything or understand anything". Based on the issue of lack of expertise, skills knowledge among practitioners would be challenged to the SMPs to adopt the MBRS.

\section{Capable Resources}

Due to practitioners with limited knowledge and skills, SMPs need to ensure they have enough resources that able to 
manage the mTool and MBRS. This is important to ensure the intention to adopt MBRS among SMPs in Malaysia. Sufficient numbers of resources that capable to use mTool to key in data and produce the XBRL instance document in order to submit through MBRS. For respondent G1, that has mentioned on their employees, which stated "Right now it's actually about 10. Most of them are not from Accounting background. In addition, they feel very difficult to key in the sheet, the details. What they think is that they do not want to do". Besides that, SMPs need to have a team that capable to handle the MBRS. But due to limited knowledge and skills, this could be challenge to the SMPs. As mentioned by $\mathrm{AC} 1$ and $\mathrm{AC} 2$ on the related to employees, which is stated "We already decided that Ira will handle the financial statements, supported by the rest of us. We need to struggle. Maybe top management will think about it first. Because we have requested for staff with Accounting background, but we thought that he/she might not be able to understand the secretary jobscope. Sometime they don't know how company secretary works". Respondent has also really concerned on the employees that have sufficient knowledge in accounting which capable to manage mTool. This is because the difficulty is when SMPs need to find capable employees which also supported by respondent $\mathrm{C} 1$. They mentioned that "Its better to have the knowledge, but not so easy to get the staff if we're having many to do the same thing. because I also have attended one, even though I have Accounting background I personally think that there's a lot of thing. we have the responsibilities to submit it. We are the team that need to do all the things for client". Therefore, limited capable resources in the SMPs will challenge the adoption of MBRS.

\section{Capability of Preparers}

Based on the implementation of MBRS, which there are two roles, that importance to manage MBRS submission. Corporate Secretary will be a lodger to submit XBRL instance document through MBRS. Corporate Secretary could also be a maker that will prepare the data and produce the XBRL instance document. Other practitioners such as auditors or accountants could also be part of maker to prepare XBRL instance document. But, there is uncertain of role on the preparer of instance document would also challenge the adoption of MBRS. As identified by respondent $\mathrm{C} 1$, "As a secretary, we just responsible to submit, and to fill in all the information". While respondent G1 emphasised "You know how SSM actually look into these matters? The way they do it is that it is the company secretary's responsibility. No matter how we fight, at the end of the day, someone has to do it. We are the lodgers. Our name is actually put into the system you know. Anything about SSM will return to me, you know. We must assign someone to be the maker". The role as maker and lodger could be confusion to practitioners when corporate secretary and auditors are having different capability and responsibility. In this case, auditors might uncertain with their roles in adoption MBRS. They would unsure with how they could play their role in preparing and submitting the XBRL instance document. As the respondent RJ2 which recognised the role of corporate secretary as they found "there is no push factor to encourage them choosing to be a company secretary. I think when MBRS is being implemented only then people will aware about company secretary". As for the early stage of the implementation of MBRS, corporate secretary is one of the important role to manage the MBRS even though there is limited of knowledge and skills. This is because respondent AC2 has emphasised on the role which they found "Because when we need to create maker, which we are not sure whether it is reliable or not. So, the responsibility is on company secretary. Right now, they are going for implementation. That is why they wanted the company secretary to do all their works". This is also supported by respondent N1 which also indicated that the role as a maker for XBRL instance document is still uncertain for corporate secretary. This is based on respondent N1: "At one stage, the SSM said that the maker is up to secretary. But the, to whom we need to pass the responsibility? No one wants to take the responsibility. As a maker, we have to handle everything related to it". Therefore, the capability of makers as preparers for using mTool in order to prepare the XBRL instance document has shown as challenge to adopt MBRS.

\section{Cost of Filing}

As SMPs, they are also concerned on cost of filing which may incur to any additional cost to prepare the XBRL instance document. There is a cost that they need to consider when there is an additional work to prepare the document. The cost that incur also will impact the practitioners when they need to charge an extra additional expenses to the client. There is also charge that incurred due to the software license that given by the software vendor when the tools and software has been embedded with the XBRL. As mentioned by respondent G1, "Even for the license its already expensive. How they earn is by way of per submission". This is also supported by the respondent $\mathrm{C} 1$ when the charge for cost of submission will be added additional cost. Respondent $\mathrm{C} 1$ mentioned that "Extra charge, is it? Of course, they should charge it. Because the system is not cheap. But we wouldn't know much they charged us for each click. They will give one sum or range how much". For the cost of filing, practitioners need to inform their future clients in order to aware with any additional cost. As highlighted by respondent AC4, "Since 2018, we already informed them about the advantages about this system for accountants and auditors. Its just that for audit, we didn't charge them yet. Because its still at the counter for now". However, there is also reluctant of 
implementation towards the submission using MBRS. This is due to respondent AC that mentioned "Majority of users do not agree with the implementation since it can be considered wasting the time. The client also curious over the expected increase of amount charged to them. SSM should devise an act that it is compulsory to pay to company secretary. At least the client will understand. If not, they asked us to do the additional task but the there is no increment in the payment". This also supported by respondent N1, "But the customers, they are quite reluctant to pay the fee charged on them". Due to issue discuss, the cost of filing could be challenged to the practitioners due to increase of cost for preparing the XBRL instance documents.

\section{Management Readiness}

Due to proceed with the adoption of MBRS, management of SMPs need to ensure the readiness of the organisation. This is also related to the resources that they have to manage the mTool and MBRS. The readiness of management among SMPs need to ensure practitioners in the practice is able to manage both mTool and MBRS. This is because practitioners have possibility to submit both the manual and XBRL instance document to the SSM until SSM has enforced the submission of XBRL instance document. In example from respondent $\mathrm{C} 1$ in preparing towards the implementation of MBRS. As respondent C1 explain, "We do not touch MBRS. We try to ask them to submit hardcopy first because sometimes it is not ready. It is not easy for us to do submission. However, I follow the audited one. I think it is only the matter of time that we go into system. I think we should be able to meet the requirement but do not know when is the final. We still need time to get ready. We do not know when the final is. Because last time we attend it, it is a lot amendment. Maybe they take feedbacks from us, and then we will see how to do. Because now we cannot worry. There is nothing to be worried over. We cannot change anything. If we do not do, we are screwed. Then later, it takes time". Furthermore, the practitioners also ensure the readiness would be developed based on the effort that done by the SMPs on trying to prepare the XBRL instance document. However, the SMPs still not showing the readiness on preparing and submission by trying to use mTool and MBRS. By respondent G1 emphasised that there is lack of readiness to be confidence with the system. Respondent G1 show, "Right now, I don't want to think too much. Let us just wait and we will see how until the implementation. I just relaxed first and then I will do". But, there is a aware by the management to ready with the implementation of MBRS when respondent G1 stated on the journey, "Slowly. Just try and error first. That is the best that we can do. If you always give the same excuse that you don't have the time to learn it, then you'll end up gaining nothing". Support by the respondent L1 which SMPs cannot refuse to learn and ready with the used of MBRS. Since MBRS will also being enforced by SSM towards the companies. From the respondent L1 that seen aware the need to be ready when they concerned on how practitioners could practice the MBRS. This is as mentioned by respondent L1, "I told my secretary that either way, we need to this as this is our bread and butter. This is your service then you need to know your client. If you didn't do it, you will never know your ability". Therefore, the management readiness towards the usage of MBRS has shown challenge to the SMPs to adopt MBRS.

Time Usage

Prior to the adoption of MBRS, practitioners also have a lot of task of accounting, auditing and secretarial works. The preparation of XBRL instance document using mTool will also impact the practitioners when they need to allocate sufficient time and the fastest as they can in order to prepare XBRL instance document for submitting through MBRS. With related to limited knowledge and skills in managing accounting, there is also impact how practitioners could manage the usage of mTool and MBRS. The challenge is also involved the time that need to be used by practitioners whether for corporate secretary or auditors. Most of the four practitioners has raised on the time that future practitioners would spend the time for preparing the XBRL instance document using mTool. As mentioned in preparing the unaudited financial statements by respondent G1, "Just for those unaudited financial statements, I need about 3 hours, to zip a file. I need about 2-3 hours. I tried to look into that and it took me more than 4 hours. I think it about 5 hours. Because I incorrectly key in the data for a few times. So, they actually expect the company secretary to be able to do it. Even in 4 hours, that doesn't guarantee that it can be zipped". There is different usage of time to prepare whether AR or FS, which FS could have a lots of items that need to fill in using mTool. The challenge happened when there is a need to prepare for FS. As mentioned respondent L1 that related to practitioners, "Once an auditor told me, although I'm the practical auditor, when he himself wants to do FS for more than ten years, it took him 4 hours. Even though he is a practical auditor. How much is the data or how long it will take. It depends on how big the accounts you do. Previously, I talked to my team; we have that one case where we need to submit annual return. It is quite fast. We already know the statement; we should not search it from system to here, but from here to the system instead. It is try and error process". Furthermore, the usage of time due to the knowledge that we have and able to utilise in preparing the FS. This is also because practitioner especially the corporate secretary have limited accounting knowledge and skills. As experienced by respondent AC4, which related to practitioner that have limited 
knowledge in accounting, "It might be tough for those who did not have basic in Accounting. For active company, one might take one whole day to settle for one company. One company, the minimum is 4 hours. Yeah, last time I did, it took me for about one day. But that only for normal company which transactions does not involve millions. If the amount is zero, we cannot put zero. Also, there is part where we need to explain and provide evidence". Furthermore, the other respondent also raised the same matter on the time that they need to use in using mTool, which key in the data in FS. The items for FS could be shown complicated with various items that being used. Based on the experiences by respondent $\mathrm{AC} 2$ which emphasised "the problems arise when generating the information. Failures to generate is common. Most of the time it is not tally. It really consumes our time", while respondent AC1 mentioned on "As for accounting part, there are some amount due. For amount due, we need to copy paste put it in the Notes. If there are many transactions, it will require a lot of time". In addition, respondent AC4 stressing on the time usage, "We are struggling so much right now, and by adding financial statements, we are literally screwed. We afraid that we have no time to do it" and there is a need to spend longer time to prepare for FS as also raised by respondent AC1. This is because $\mathrm{AC} 1$ also mentioned "That is why we took minimum 4 hours. For those with accounting background, it will be okay I think as they understand the wording". This is also supported by respondent $\mathrm{N} 1$ on related to corporate secretary on the time that spending on the mTool. This is because corporate secretary is responsible as maker and lodger for XBRL instance document. Respondent N1 raised the matter that related, "Some secretaries said that they took some time to do for FS of an active company, the fastest they can do is minimum 3 hours. In a day, about 3 active company can be completed. Mostly, including me, it will take about half day. The fastest I heard from my friends is 3 hours. That's because they are used to it. For us which are not really used to it, will consume much more time". Thus, the time has shown challenge to the SMPs since it is related to the knowledge and skills among practitioners. Due to limited resources and practitioners that have sufficient knowledge and skills in accounting, there is a challenge in spending sufficient time to use mTool and MBRS. Therefore, the time usage is a challenge to adopt MBRS.

\subsection{Environmental Factors}

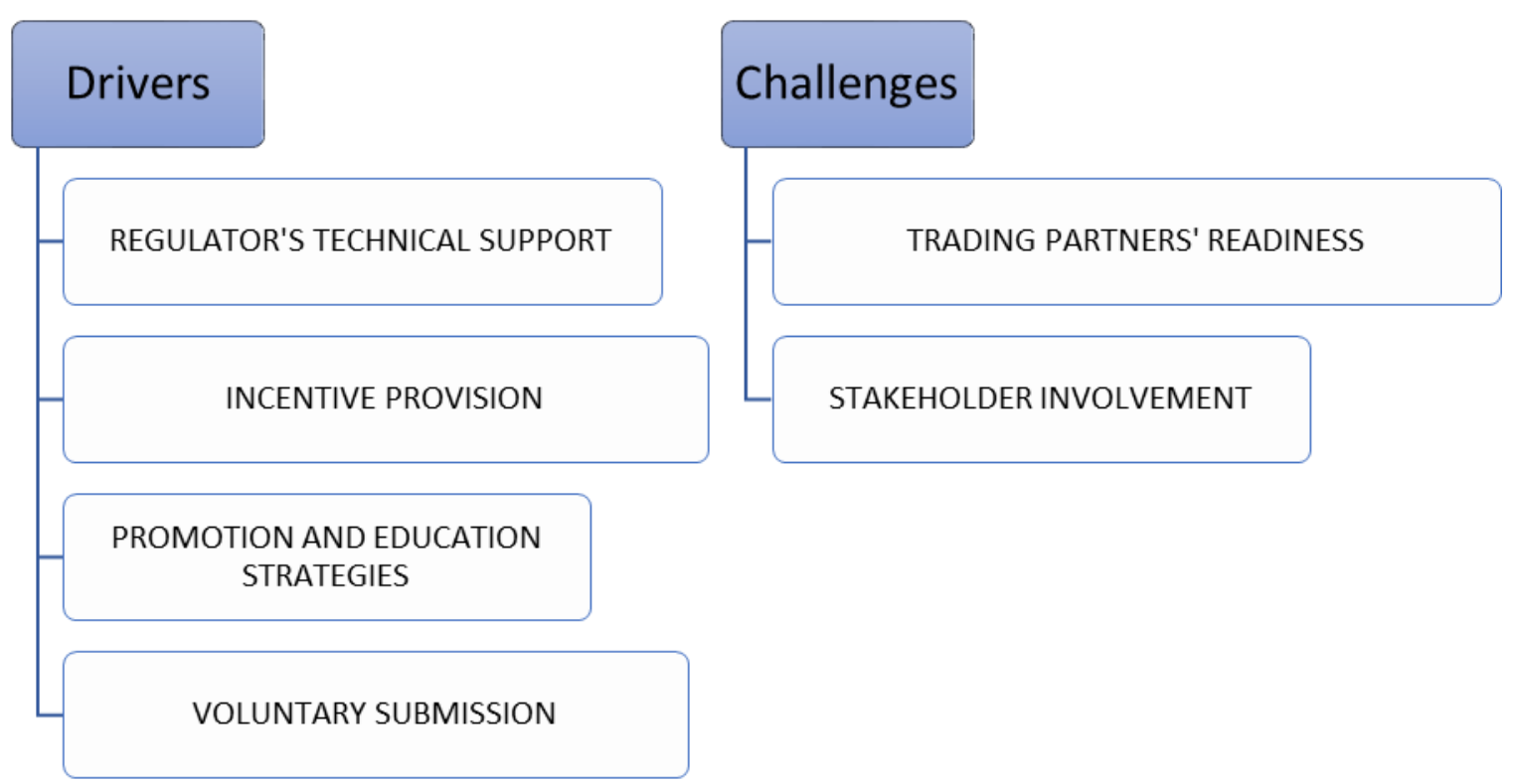

\section{Regulator's Technical Support}

In this study, government support is driver on practitioners' experience in using mTool and MBRS. This is because the assistance from regulator has seen to be helpful to practitioners that responsible to use mTool in preparing the XBRL instance document, together with the submission through MBRS. This is because respondent AC2 has shared on the support, "It depends on the SSM officer. We can say that they are helpful". Due to the new system, practitioners really need to communicate with SSM in order to ensure the data has been keyed in according to the requirements in order to produce high quality information. As mentioned by respondent $\mathrm{C} 1$ on the need to communicate with SSM, "Because, even if we have the system, we still need to communicate. Because wide 
information we need to submit. Because, some controls for current report all are required. Whether the system is called function or whether all information are captured accordingly". However, the numbers of companies in Malaysia would also affect the SSM operate and manage the way to provide technical help for MBRS. As found from respondent AC3, "It does take some time. Because, SSM need to entertain a large number of companies, and we are one of them. We can understand that". This is because respondent AC4 has suggested that the SSM are responsible to concern on how corporate secretary involved in the implementation of MBRS. As mentioned by respondent AC4, "If the regulator can come and see how company secretary do our work, it would be better". Therefore, the support from regulator is not a challenge to SMPs in order to adopt MBRS.

\section{Incentive Provision}

SSM should identify how the best way to attract practitioners in preparing with the usage of mTool and MBRS. This can be considered important to ensure practitioners are ready to use MBRS. This has been raised by practitioners that concerned on how to attract corporate secretary as lodger and maker for AR and FS. As mentioned by respondent RJ1 that raised "who fully compliant to MBRS should be given incentives". Furthermore, other respondent RJ2 that they have think of the way to provide incentive to practitioners. They have mentioned to suggest to SSM "to give credit for those who comply to MBRS. Extra mark should be given which may be beneficial for them to renew license, or merit that would ease their future task. Alternatively, even free CPD marks that is quite essential". While, respondent RJ1 also emphasised on the CPD marks that given by SSM to corporate secretary. As respondent RJ1 suggest that "for company secretary who submit full set of financial statements, give them credit score or CPD point. For those who can submit full report, they must be given credit score to reflect their compliancy. The minimum you must submit is the KFI. KFI means the total asset, total liability, capital, reserve, revenue, COGS, total depreciation and appreciation. The secretary should do these first for them to get the hang of it. If not, it would be so detailed". Even though SSM has ensure the available ready template and submission platform, SSM could also need to ensure the incentive given to the practitioners that adopt MBRS.

\section{Promotion and Education Strategies}

In order to ensure the implementation of MBRS will be successful, SSM could identify effective promotion strategies. These strategies will ensure practitioners will fully aware on how MBRS could ease the work of practitioners as well as the benefits. Furthermore, practitioners will be more aware the way MBRS will be implemented and how the preparation of AR and FS. This is because some of practitioners might be not aware on the implementation of MBRS due to lack involvement at the development of MBRS. In this implementation of MBRS, there is proven that there is not an issue on awareness of AR compared with FS. This is because respondent C1 mentioned, "We are not fully using it for FS because only on annual return". This is also supported by respondent G1 when they mentioned "its wide on annual return. There is annual return and another one is the financial statements. In addition, that one we have not really have the exposure to key in FS. I can tell you that not many company secretary has exposure". Furthermore, promotion that done by SSM could also ensure practitioner will be aware with the benefit of MBRS to corporate secretary. This is due to respondent RJ1, "For us, we are still new and we look forward to learn new thing if anyone willing to teach us. The knowledge about the system is beneficial". However, this might not being aware to auditor as also mentioned by respondent RJ2, "As far as I'm concerned, we don't really expose to MBRS in here to auditors". Even though, most of the responsibility is related to corporate secretary, the process to use mTool and MBRS must also be aware by practitioners. This will make it easier to prepare the XBRL instance document for AR and FS. The respondent AC2 has mentioned that "Because currently, MBRS are available for annual returns, financial statements, audited and unaudited accounts. So there are three things. Okay, for annual return, any company should aware and must know about its process".

Beside practitioners, this promotion should be done for companies. This is because companies are required to submit AR and FS through MBRS with the assistance of the corporate secretary. Due to the cost of filing that may increase when submitting through MBRS, SSM should work with SMPs to ensure companies are aware with the implementation of MBRS. The respondent G1 has stated their plan in ensure the readiness of MBRS, "we try to tell the client that this MBRS thing, the online submission of the audited accounts needed accounting will be implemented soon please ask your accountants to go and take classes". This is also supported by respondent N1, "to educate the people, educate the directors of the companies for them to apply the acts that have been regulated. So, for them it is for the sake of educating the intended users. But they couldn't see the burden that users are facing. It is heavy". Furthermore, SSM has implement their programme to educate practitioners to manage the usage of MBRS. This has been stated by respondent $\mathrm{C} 1$ on the evidence of attended training. The respondent $\mathrm{C} 1$ has mentioned that "I attended last year's training, the course was for MBRS. I think only one. Because I think the course are the same". 
Therefore, the promotion and education strategies done by SSM has drive the usage of MBRS based on the issues of awareness among practitioners.

\section{Voluntary Submission}

The submission of XBRL instance document has started with voluntary submission at the early stage of implementation of MBRS. With the voluntary submission that still allowed with the over the counter submission and online for FS. As mentioned by respondent C1, "Report is at the counter. For audit report, we need to make adjust ratifications online" and G1 raised on "Because now we can still submit over the counter. Just submit it there". However, the voluntary submission also need to take some time to ensure the data is update in the system. As mentioned by respondent $\mathrm{AC} 1$ and $\mathrm{AC} 3$, "There are also some forms that need to be submitted by hand over the counter. When it is submitted over the counter, it will take some time to up to date it. there is still certain documents that need to be submitted over the counter. For the document, it must follow up to date. If submit online, it is automatically updated on the spot, but if it is submitted over the counter, it will take some time".

In suggestion with the voluntary submission by SSM, this could encourage willingness among practitioners to try to experience the mTool. However, the willingness to use mTool in preparing the AR and FS need to ensure the clear role of corporate secretary or other practitioners. As raised by respondent L1 that shown willingness to try with the MBRS as mentioned, "For me, instead you are saying that you have knowledge in accounting or not, if you dare to try, the first thing is you must dare to try. You must have the spirit. If you don't, you refuse to try, just sit there and say "I don't know, I'm afraid to, afraid of doing mistakes", it will end up the same. Regardless of whether you have the knowledge or not. So, we must be willing to try". Respondent AC1 has shown also the effort to use MBRS as mentioned by respondent $\mathrm{AC} 1$, "We all have tried preparing the FS, for our own preparation so that we can get the hang of it and understand how to do it". But there is also possibility not to put effort in submission the FS through MBRS as also mentioned by AC3 and AC4, "Right now it is not mandatory yet. It already has. It should already start by now. But many people are reluctant to do it. As for company secretary, we won't do it unless it is compulsory". Therefore, this method of submission could encourage the usage of MBRS among practitioners. This is because this voluntary submission would ensure the readiness towards MBRS.

\section{Trading Partners' Readiness}

In ensuring the MBRS could be accepted in the communities in Malaysia, there is a need to ensure the readiness of each partner that involved. In this study, there is limited readiness among trading partners since there is a proven that each practitioner might not ready with the responsibility towards the implementation of MBRS. Based on respondents' perspective, most of them are concerned on the burden due to managing the mTool and MBRS. The practitioners that related to the trading partners which is involved accountant, corporate secretary as well as auditor in order to ensure the successful of MBRS. This is because there are two roles which is maker and lodger of XBRL instance document that will involve each partner. Furthermore, practitioner in this study has not ready with a new task that exist from MBRS. Based on respondent C1 stated "It gives us a lot of stress. Even the commitment is limited, but we also involved. But, in future, probably it will be a lot harder". The issue among partners are related to the burden from the MBRS implementation among practitioners specifically to corporate secretary. As raised by respondent AC1, "the responsibility to check is given to us. The burden that company secretary have is increasing" and respondent AC2 also raised, "we already feel the burden since they started to incorporation online. Because when we need to create maker, which we are not sure whether it is reliable or not. So, the responsibility is on company secretary". There is burden on time usage toward the preparation of FS through mTool as mentioned by respondent AC4, "Because, for system, we need to check properly, deal with the client and SSM which require a lot of time. This does not include Financial Statement just yet. We focused more on company secretary. We need to know how to key in Asset, Liabilities and everything. It might be tough for those who did not have basic in Accounting". Besides on the burden issue, there is also to ensure the readiness of maker to prepare the XBRL instance document from the mTool. As mentioned earlier, corporate secretary need to be a lodger and any other practitioner is able to be maker of XBRL instance document. But, the finding in this study shown from the respondent $\mathrm{N} 1$ which is related to the readiness to be whether lodger or maker. As mentioned by $\mathrm{N} 1$ which is "A lodger only lodge it, but as a maker, to do all those things, its just too much because no one's ready to take the responsibility. Everyone is busy. Another thing is that we already have too much tasks on hand, to add another requirement, it will require a lot more time from us. For MBRS, we are already burdened by the existing workload, if there is another responsibility we need to bear, the burden is heavier. No one wants to be the maker". In addition, the other practitioners could need to be ready with the MBRS. This is because to ensure the XBRL communities in Malaysia will be ready in the market. There is issue that raised on the accounting perspective that respondent AC1, "Accounting people already have their own tasks, if we ask for their help, for sure it is not free. Even 
if we ask auditor's help to generate it, they will charge the client" and respondent AC3 also mentioned that "I think there is no problem when it comes to corporate secretary part since we can seek advice from our own team. But, for external auditors, it will be quite difficult". Therefore, the lack of readiness among partners that involved in the implementation of MBRS could be challenges to the SMPs in adopting MBRS.

\section{Stakeholder Involvement}

In this study, auditors and accountants are important together with the involvement of corporate secretary. Corporate secretary is a lodger of XBRL instance document to be submitted through MBRS. Auditors and accountants are really important in order to ensure they will be part of maker of AR and FS by using mTool. As mentioned by respondent RJ3 which related how auditor are important, "If we create financial statement from MBRS, we need information from both sides. Company secretary must get information from auditor, and vice versa. And then we'll find a solution for that data".

However, their involvement as stakeholder in this communities of XBRL could be important in order to reduce the burden of corporate secretary. As mentioned by respondent RJ2 which is "we have simply discussed about whether the auditor or the company secretary that would need to key in the data. But, so far there is no in-depth discussion about this, and right it is done by company secretary". This is also supported by respondent AC1, "I think if the company's auditor can do this instead of company secretary, I think it would be better". Furthermore, the challenge could happened when auditors are refuse to involve in the implementation of MBRS. As mentioned by auditors from the SMPs as stated by respondent N1, "When I ask the statutory auditors, the auditors here are different. All company secretaries said, you are the auditor so you need to bear this responsibility. It's not that they doesn't want to be strict, but it's just hard". Based on the issues discuss on the involvement of stakeholder which is auditor involvement, this could be challenge to the usage of MBRS.

\section{Conclusion, Limitation and Future Study}

Based on the TOE theory, there are 20 factors that discovered from the technological, organisational and environmental context that related to adoption of MBRS among practitioners particularly corporate secretary. In related to technological context, there are three factors that drive the continuous of adoption for MBRS. They are confident on how XBRL could provide assurance for data quality, relative advantage and the availability of regulator's platform and system. Therefore, RO1a has shown three technological factors as drivers to the adoption of MBRS. However, they are worried on limited tools and software, compability of format, compatibility of content and how the mTool could provide ease of use to the corporate secretary as maker and lodger. By comparing to past studies, relative advantage has seen to be common to most of the studies done with regulators (Mousa, 2010; Henderson et al., 2012) as well as assurance of data quality (Ilias, Ghani \& Azhar, 2019). While, the availability of tools and software (Troshani \& Doolin, 2005; Troshani \& Rao, 2007; David, 2016) is commonly as challenge to the adoption of XBRL. With comparison with the compatibility (Cordery, Fowler \& Mustafa, 2011), this current study has discovered two different compatible for both format and content that produce from the use of mTool. Therefore, RO1a has shown four technological factors that seen to challenge to the adoption of MBRS.

In this study, there are organisational factors that influence the adoption of MBRS. From the perspective of SMPs which they need to ensure the readiness amomg practitioners towards the enforcement of MBRS in future. There are seven challenges that can be considered discovered from organisational which are challenge to face attitude of preparers, limited practitioners that have own sufficient skills and knowledge, limited capable resources and preparers to manage the mTool. There is also concerned on the change of cost of filing that SMPs would need to be ready which is also related to their clients. Besides that, SMPs need to also ensure the readiness of their firms and also the time that they need to use mTool to produce XBRL instance document for AR and FS. Based on the past studies, the factor that related to knowledge (Troshani \& Doolin, 2005; Henderson, Sheetz \& Trinkle, 2012), skills and resources (Mousa, 2010; David, 2016), management readiness (Doolin \& Troshani, 2007) are the common factors. Since this current study concerned on the corporate secretaries' perspective, the attitude and capability with the time of usage of preparers are one of their major concern in order to continuously adopt MBRS. Therefore, RO1b has shown seven factors that contributed to the adoption of MBRS which factors are considered as challenges to the SMPs.

Together with the technological and organisational, factors of environmental context would also played important role in order to ensure the readiness to adopt MBRS among the communities. In order to ensure the adoption among SMPs in Malaysia, the technical support from regulator is considered important and SSM could also need to consider on the provision of incentive that should be given to the practitioners or SMPs. Besides that, the effective strategies for promotion and educate practitioners that has seen to show actively done by SSM would encourage the adoption 
of MBRS. With this, SSM need to ensure the method that they decided to use would attract practitioners to start with the voluntary submission. Therefore, RO1c has shown four environmental factors has drive to attract the adoption of MBRS among practitioners for the SMPs. However, the lack of readiness on the use of mTool and MBRS among trading partners and other stakeholder involvement would also challenge the adoption of MBRS. This current study has shown similar factors on promotion and education strategies and stakeholder involvement as suggested by David (2016). Most of the studies are concern on the trading partners (Henderson et al., 2012; Garner et al., 2013; David, 2016), which ensure the adoption of XBRL, however this currents study has focus on their lack of readiness would challenge the adoption of MBRS. This current study has contributed to the factors that related to incentive provision, regulator's technical support and voluntary submission method which can attract the adoption among practitioners. Therefore, RO1c has shown two environmental factors that challenge the SMPs to ensure the adoption of MBRS. In generally, this study is able to contribute to the research of XBRL from the perspective of practitioners which is focused on corporate secretary as the main role of MBRS implementation in Malaysia. By comparing to the past studies that mostly concerned on the regualators' perspective (Ilias, Ghani \& Azhar, 2019; Mousa, 2010). This will show that there is different of view on the factors of adoption of MBRS from both regulator and practitioners. This is important to ensure both parties will be ready on the adoption prior to the enforcement of mandatory submission.

This study is conducted with limitations due to the selected respondents that comprises of only 12 corporate secretaries as practitioners from SMPs. This study only concerned on the corporate secretaries as the main role of the implementation of MBRS in Malaysia in sharing their experiences in the adoption of MBRS. Thus, the current study did not capture the other practitioners' experience of XBRL due to limited experience to use MBRS. Future studies should be carried out in post-implementation to identify how MBRS will give impact to the other practitioners from SMPs such as auditors, tax agents and accountants.

\section{Acknowledgement}

We wish to thank the Universiti Tenaga Nasional Malaysia for IRMC PUBLICATION FUND (RJO10517919/iRMC/Publication) and Universiti Teknologi MARA for their support and funding.

\section{References}

Alles, M. G., \& Gray, G. L. (2012). A Relative Cost Framework of Demand for External Assurance of XBRL Filings. Journal of Information Systems, 26(1), 103-126.

Bakajic, M. (2015). Analysis of decision makers' perceptions of XBRL prior to adoption.

Bergeron, B. (2003). Essentials of XBRL: Financial Reporting in the 21st Century. Wiley.

CFA Institute. (2016). CFA Institute Member Survey: XBRL December 2011. CFA Institute Market Research. Retrieved from https://www.cfainstitute.org/en/research/survey-reports/xbrl-member-survey-report-2016

Cordery, C. J., Fowler, C. J., \& Mustafa, K. (2011). A solution looking for a problem: factors associated with the non-adoption of XBRL. Pacific Accounting Review, 2(1), 69-88.

Cox, C. (2006). Speech by SEC Chairman: The Promise of Interactive Data. $14^{\text {th }}$ International XBRL Conference Philadelphia. Pennsylvania. Retrieved from http://www.sec.gov/news/speech/2006/spch120506cc.htm

David, J. (2016). The non-adoption of XBRL by professional and government organisations in New Zealand and its implications for stakeholders. (Ph.D), Victoria University of Wellington. Retreived from http://researcharchive.vuw.ac.nz/xmlui/handle/10063/5459

Debreceny, R., \& Gray, G. L. (2001). The production and use of semantically rich accounting reports on the Internet: XML and XBRL. International Journal of Accounting Information Systems, 2, 47-74.

Depietro, R., Wiarda, E., \& Fleischer, M. (1990). The Context for Change: Organization, Technology and Environment. The processes of technological innovation. Lexington, Mass.: Lexington Books, 151-175.

Doolin, B., \& McLeod, L. (2005). Towards critical interpretivism in IS research. In D. Howcroft, \& E. M. Trauth (Eds.), Handbook of critical information systems research (Vol. 36, pp. 244-271). Edward Elgar Publishing Limited. https://doi.org/10.1016/j.chemphys.2005.04.044

Doolin, B., \& Troshani, I. (2007). Organizational Adoption of XBRL. Electronic Markets, 17(3), 199-209. https://doi.org/10.1080/10196780701503195

Dunne, T., Helliar, C., Lymer, A., \& Mousa, R. (2013). Stakeholder engagemnet in internet financial reporting: The diffusion of XBRL in the UK. The British Accounting Review, 45, 167-182. 
Dunne, T., Helliar, P. C., Lymer, A., \& Mousa, R. (2009). XBRL: The Views of Stakeholders. Reserch Report. The Association of Chartered Certified Accountants.

Efendi, J., Smith, L. M., \& Wong, J. (2011). Longitudinal Analysis of Voluntary Adoption of XBRL on Financial Reporting. International Journal of Economics and Accounting, 2(2), 173-189. Retrieved from http://papers.ssrn.com/sol3/papers.cfm?abstract_id=1440956

Felden, C. (2011). Characteristics of XBRL adoption in Germany. Journal of Management Control, 22(2), 161-186.

Garner, D., Henderson, D., Sheetz, S. D., \& Trinkle, B. S. (2013). The Different Levels of XBRL Adoption. Management Accounting Quarterly, 14(2), 1-10.

Ghani, E. K., Laswad, F., \& Tooley, S. (2009). Digital Reporting Formats: Users' Perceptions, Preferences and Performance. The International Journal of Digital Accounting Research, 9, 45-98.

Henderson, D., Sheetz, S. D., \& Trinkle, B. (2011). Understanding the Intention to Adopt XBRL: An Environmental Perspective. Journal of Emerging Technologies in Accounting, 8, 1-46.

Henderson, D., Sheetz, S. D., \& Trinkle, B. S. (2012). The determinants of interorganizational and internal in-house adoption of XBRL: A structural equation model. International Journal of Accounting Information Systems, 13, 109-140.

Henderson, D., Sheetz, S. D., \& Trinkle, B. S. (2012). The determinants of interorganizational and internal in-house adoption of XBRL: A structural equation model. International Journal of Accounting Information Systems, 13, $109-140$

Hoffman, C. (2006). Financial Reporting Using XBRL, IFRS and US GAAP Edition. UBMatrix.

Hsieh, T. S., Wang, Z., \& Abdolmohammadi, M. (2019). Does XBRL disclosure management solution influence earnings release efficiency and earnings management?. International Journal of Accounting \& Information Management, 27(1), 74-95. https://doi.org/10.1108/IJAIM-06-2017-0079

Ilias, A., \& Ghani, E. K. (2015). Examining the adoption of extensible business reporting language among public listed companies in Malaysia. Procedia Economics and Finance, 28, 32-38.

Ilias, A., Ghani, E. K., \& Azhar, Z. (2017). XBRL Adoption in Malaysia: Perception of the Accountants and Auditors. International Conference on Accounting Studies (ICAS) 2017 (1-10). Putrajaya.

Ilias, A., Ghani, E. K., \& Azhar, Z. (2019). Factors Influencing Knowledge and Persuasion of Financial Regulators in the XBRL Adoption Process: The Technological Perspective. International Journal of Financial Research, 10(3), 170-180.

Ilias, A., Razak, Z. M. A., \& Razak, S. F. F. A. (2015). The awareness of the extensible business reporting language (XBRL) in Malaysia. The Journal of Internet Banking and Commerce, 19(2), 1-26.

Ilias, G., \& Azhar. (2019). Understanding XBRL Adoption Process and Adoption Type among Regulators: A Malaysian Evidence. International Journal of Innovation, Creativity and Change, 7(9), 144-163.

Janvrin, D., Mascha, M., \& Pinsker, R. (2011). XBRL, Excel or PDF? The Effects of Technology Choice on the Analysis of Financial Information. $\quad$ Retrieved from https://papers.ssrn.com/sol3/papers.cfm?abstract_id=1740249

Klimczak, K. (2019). The Benefits of Using XBRL for Reporting on Capital Markets in the Light of Market Supervisors Reports and Scientific Research. Acta Universitatis Lodziensis. Folia Oeconomica, 1(340), 57-72.

Liu, C., Luo, X. R., Sia, C. L., O'Farrell, G., \& Teo, H. T. (2014). The impact of XBRL adoption in PR China. Decision Support System, 59, 242-249.

Liu, C., Wang, T., \& Yao, L. J. (2014). XBRL's impact on analyst forecast behaviour: An emperical study. Journal Accounting Public Policy, 33, 69-82. http://dx.doi.org/10.1016/j.jaccpubpol.2013.10.004

Miles, M. B., Huberman, A. M., \& Saldana, J. (2014). Qualitative data analysis. Sage Publication.

Mousa, R. (2010). E-Government Adoption Process: XBRL Adoption in HM Revenue and Customs and Companies House. (Ph.D), University of Birmingham. Retrieved from https://etheses.bham.ac.uk/id/eprint/1752/

Mousa, R. (2016). The evolution of electronic filing process at the UK's HM Revenue and Customs: The case of XBRL adoption. eJournal of Tax Research, 14(1), 206-234.

Nel, G., \& Steenkamp, L. (2008). An exploratory study of chartered accountants' awareness and understanding of 
XBRL. Meditari Accountancy Research, 16(1), 79-93.

Piechocki, M., \& Servais, O. (2010). The Role of XBRL and IFRS in Integrated Reporting. In Eccles, R. G., Cheng, B., \& Saltzman, D. (Eds.), The landscape of integrated reporting Reflections and next steps (pp. 155-159). Massachusetts: Harvard Business School.

Pinsker, R. (2003). XBRL Awareness in auditing: a sleeping giant?. Managerial Auditing Journal, 18(9), 732-736. https://doi.org/10.1108/02686900310500497

Plumlee, R. D., \& Plumlee, M. A. (2008). Assurance on XBRL for Financial Reporting. Accounting Horizons, 22(3), 353-368.

Rogers, E. M. (1983). Diffusion of Innovations (3rd ed.). New York: Free Press.

Shan, Y. G., \& Troshani, I. (2014). Does XBRL benefit Financial Statement auditing?. Journal of Computer Information System, 11-21.

Stantial, J. (2007, June). ROI and XBRL. Journal of Accountancy. Retrieved from https://www.journalofaccountancy.com/issues/2007/jun/roionxbrl.html

Steenkamp, L., \& Nel, G. (2012). The Adoption of XBRL in South Africa: an emrerical study. The Electronic Library, 30(3), 409-425.

Steenkamp, L., \& Nel, G. (2012). The Adoption of XBRL in South Africa: an emrerical study. The Electronic Library, 30(3), 409-425.

Suriakumari, P., \& Das, F. A. (2018). Factors influencing the perceived timeline to adopt XBRL amongst public listed companies in Malaysia (Doctoral dissertation, Universiti Utara Malaysia).

Troshani, I., \& Doolin, B. (2007). Innovation diffusion: a stakeholder and social network view. Europian Journal of Innovation Management, 10(2), 176-200.

Troshani, I., \& Lymer, A. (2010). Translation in XBRL standardization. Information Technology \& People, 23(2), 136-164.

Troshani, I., \& Rao, S. (2007). Drivers and Inhibitors to XBRL Adoption: A Qualitative Approach to Build a Theory in Under-Researched Areas. International Journal of E-Business Research, 3(4), 98-111.

Uyob, R. B., Bahador, K. M. B. K., \& Noh, N. S. B. (2019). Application of Technology Acceptance Model (TAM) in predicting user intention to use Malaysian Business Reporting System (MBRS): A Conceptual Paper. Journal on Technical and Vocational Education (JTVE), 4(2).

Venkatesh, R., \& Armitage, J. (2012). Accountants' Awareness And Pereption About Assurance On XBRL Financial Statements. The Journal of Applied Business Research, 28(2), 145-155.

Wahab, Z. A. (2019). Integrating XBRL and Block Chain to Improve Corporate Transparency Integrity and Availability in Malaysia. International Journal of Academic Research in Business snd Social Sciences, 9(6).

Wang, Y.-M., Wang, Y.-S., \& Yang, Y.-F. (2010). Understanding the determinants of RFID adoption in the manufacturing industry. Technological Forecasting \& Social Change, 77, 803-815.

Weber, R. (2003). XML, XBRL, and the Future of Business and Business Reporting. In D. S. Roohani (Ed.), Trust and Data Assurance in Capital Markets: The Role of Technology Solutions (pp. 3-7). PricewaterhouseCoopers LLP.

Yoon, H., Zo, H., \& Ciganek, A. P. (2011). Does XBRL adoption reduce information assymetry. Journal of Business Research, 64, 157-163.

Zhou, J. (2019). Does one size fit all? Evidence on XBRL adoption and 10-K filing lag. Accounting \& Finance, 31-52. dhttps://doi.org/ 10.1111/acfi.12444 